\title{
Redução do espaçamento entrelinhas do milho e sua influência na dose do
}

\section{herbicida $^{1}$}

\section{Narrow row spacing of corn crop and its influence on herbicide dose}

\author{
André da Rosa Ulguim ${ }^{2}$; Lais Tessari Perboni ${ }^{2}$; Nixon da Rosa Westendorff ${ }^{2}$; Marcos André \\ Nohatto $^{2}$; Bruno Moncks da Silva ${ }^{3}$; Dirceu Agostinetto ${ }^{4}$
}

Resumo - A integração de práticas de manejo como ferramenta auxiliar no controle químico de plantas daninhas, em pós-emergência na cultura do milho (Zea mays L.), pode propiciar a redução da dose do herbicida a ser aplicado. Dessa forma, o objetivo do presente trabalho foi estudar, por meio de alterações no espaçamento, a possibilidade de redução das doses recomendadas dos herbicidas tembotriona e mesotriona, sem prejudicar o controle das plantas daninhas e a produtividade da cultura do milho. $\mathrm{O}$ experimento foi realizado em delineamento em blocos casualizados em esquema de parcelas sub-subdivididas, com quatro repetições. Como tratamentos utilizaram-se dois espaçamentos entrelinhas $(0,40$ e $0,80 \mathrm{~m})$; dois herbicidas (tembotriona - $100 \mathrm{~g}$ i.a. ha ${ }^{-1}$ e mesotriona - $192 \mathrm{~g}$ i.a. ha ${ }^{-1}$ ); e, quatro doses dos herbicidas (100, 80,60 e $0 \%$ a dose recomendada). Avaliaram-se visualmente a fitotoxicidade à cultura e controle de nabo (Raphanus raphanistrum L.) e papuã [Urochloa plantaginea (Link) Hitchc.], aos 7, 14, 21 e 28 dias após a aplicação dos tratamentos, bem como o número de plantas por parcela, espigas por planta, massa de mil grãos e produtividade. Os resultados evidenciaram que o espaçamento não interferiu no controle de nabo e papuã e na produtividade do milho. O herbicida mesotriona foi mais eficiente no controle de nabo e o tembotriona de papuã, possibilitando utilizar $80 \%$ da dose recomendada de ambos sem afetar o controle de plantas daninhas e a produtividade da cultura.

Palavras-chaves: tembotriona, mesotriona, Urochloa plantaginea (Link) Hitchc., Raphanus raphanistrum $\mathrm{L}$.

\begin{abstract}
Management practices integration as an auxiliary tool in weeds chemical control in post emergence in corn crop (Zea mys L.) may reduce herbicide dose to be applied. Thus, this study aimed to evaluated by spacing changes, the reduction possibility of tembotrione and mesotrione herbicides recommended doses of and without damaging weeds control and corn yield. The experimental design was randomized complete blocks, arranged in split-plot scheme with four replications. Treatments used were two row spacing $(0.40$ and $0.80 \mathrm{~m})$; two herbicides (tembotrione - $100 \mathrm{~g}$ a.i. $\mathrm{ha}^{-1}$ and mesotrione - $192 \mathrm{~g}$ a.i. ha $\left.{ }^{-1}\right)$; and four herbicides doses $(100,80$, 60 and $0 \%$ of recommended dose). It was evaluated effect phytotoxicity visual to the crop, wild radish (Raphanus raphanistrum L.) control and alexandergrass [Urochloa plantaginea (Link)

\footnotetext{
${ }^{1}$ Recebido para publicação em 23/04/2013 e aceito em 02/04/2014.

2 Aluno do Programa de Pós-Graduação em Fitossanidade da Universidade Federal de Pelotas (UFPel), Campus Universitário Capão do Leão, Caixa Postal 354, 96010-900, Pelotas-RS. E-mail: andre_ulguim@yahoo.com.br (Autor para correspondência).

${ }^{3}$ Aluno de graduação da Faculdade de Agronomia Eliseu Maciel, UFPel.

${ }^{4}$ Professor da Faculdade de Agronomia Eliseu Maciel, UFpel.
} 
Hitchc.] at 7, 14, 21 and 28 days after treatment application), as well as the number of plants per plots, ears per plant, thousand grain mass and yield. Results evidenced that spacing did not interfer in wild radish and alexandergrass control and in corn yield. Mesotrione herbicide was more efficient in wild radish control, and tembotrione for alexandergrass control, allowing the use $80 \%$ of recommended dose for both herbicides without affecting weeds control and corn yield.

Keywords: Tembotrione, mesotrione, wild radish, alexandergrass

\section{Introdução}

O milho (Zea mays L.) é um cereal de grande importância na alimentação animal e humana e também como matéria-prima na produção de energia. O Brasil é o terceiro maior produtor mundial de milho. Entretanto, a produtividade média de quatro toneladas por hectare é considerada baixa em relação a países como Israel e Estados Unidos (FAO, 2012).

As causas da baixa produtividade brasileira são justificadas pelos diversos sistemas de cultivo, finalidade da produção e nível tecnológico dos agricultores. O manejo inadequado das plantas daninhas interfere na produtividade, podendo ocasionar perdas que variam de 10 a $80 \%$, dependendo da espécie e população das plantas daninhas, período de competição, estádio da cultura e condições edafoclimáticas (Vargas et al., 2006).

O controle químico constitui no principal método utilizado pelos agricultores no manejo das plantas daninhas na cultura do milho. No entanto, estratégias centradas em único método de controle podem selecionar plantas daninhas resistentes a herbicidas, pela alta pressão de seleção exercida. O controle cultural, dentro do manejo integrado de plantas daninhas na cultura do milho (MIPD), é ferramenta essencial para reduzir o impacto ambiental dos herbicidas.

O arranjo espacial das plantas de milho constitui-se em prática de manejo cultural importante para obtenção de produtividades próximas ao potencial produtivo da cultura (Argenta et al., 2001). A redução do espaçamento entre linhas de milho contribuiu para o controle de plantas daninhas que se estabeleceram tardiamente na área cultivada
(Shresta et al., 2001). Através da redução do espaçamento, diminui-se a competição intraespecífica pela distribuição equidistante das plantas na linha de cultivo, melhorando o uso da água, de nutrientes e a interceptação de luz (Demétrio et al., 2008), favorecendo a cultura na competição interespecífica (Teasdale, 1995; Nice et al., 2001).

$\mathrm{O}$ aumento da capacidade de interceptação de luz pelo dossel da cultura favorece a ocupação mais rápida do espaço, diminuindo a disponibilidade de recursos ao crescimento e desenvolvimento de plantas daninhas (Tharp \& Kells, 2001). A interceptação de luz pelo dossel da cultura do milho foi maior quando da redução do espaçamento entrelinhas, comprovando que a semeadura em arranjos espaciais mais equidistantes dificulta o acesso das plantas daninhas a este recurso (Flénet et al., 1996; Kunz et al., 2007). Sob reduzida quantidade de luz, a taxa fotossintética das plantas daninhas diminui, o que reduz o potencial de dano dessas plantas às culturas (Norris et al., 2001).

A maior interceptação da radiação fotossinteticamente ativa exerce influência na produtividade do milho, quando outros fatores ambientais são favoráveis (Ottman \& Welch, 1989). Estudos de redução do espaçamento entre linhas sobre produtividade de grãos de milho apresentam resultados bastante heterogêneos, indicando aumentos da produtividade de grãos, com a redução do espaçamento entre linhas (Shresta et al., 2001; Johnson \& Hoverstad, 2002; Balbinot Junior \& Fleck, 2005; Strieder, 2006), e/ou que não apresentaram incrementos significativos na 
produtividade (Teasdale, 1995; Nunes et al., 2004).

Várias são as opções de controle químico de plantas daninhas em pósemergência na cultura do milho e entre os herbicidas utilizados encontram-se tembotriona e mesotriona. Estes herbicidas pertencem ao mecanismo de ação dos inibidores de carotenoides, e além de serem seletivos a cultura do milho, controlam plantas daninhas eudicotiledôneas e monocotiledôneas. As doses dos herbicidas são recomendadas em quantidades que assegurem amplo espectro de ação sob diversos níveis de suscetibilidade e condições ambientais, que na maioria das vezes, são diferentes daquelas consideradas ideais para ótima ação do herbicida (Vidal, 2002). Em alguns casos, as doses recomendadas de alguns herbicidas podem ser reduzidas sem prejuízo para o controle das plantas daninhas e sem afetar a produtividade das culturas (Defelice et al., 1989; Fleck et al., 1997).

A adoção de espaçamentos reduzidos associado ao controle químico é estratégia de grande importância no manejo sustentável de plantas daninhas, sobretudo para determinados genótipos com arquitetura mais ereta e mais competitivos (Balbinot Junior \& Fleck, 2005). Assim, o objetivo do trabalho foi estudar, por meio de alterações no espaçamento, a possibilidade de redução das doses recomendadas dos herbicidas tembotriona e mesotriona, sem prejudicar o controle das plantas daninhas e a produtividade da cultura do milho.

\section{Material e Métodos}

O experimento foi conduzido a campo ( $31^{\circ} 48^{\prime} 03^{\prime \prime} \mathrm{S}, 52^{\circ} 30^{\prime} 03^{\prime \prime} \mathrm{W}$; a $34 \mathrm{~m}$ de altitude), em solo classificado como Argissolo Vermelho Amarelo, de textura franco arenosa, pertencente à unidade de mapeamento de Pelotas/RS (Embrapa, 2006). As condições meteorológicas do período de condução do experimento estão apresentadas na Tabela 1.

Antes da semeadura do milho, a área foi dessecada com glyphosate (1.800 g e.a. ha $\left.{ }^{-1}\right)$. O híbrido de milho 2B65HX foi semeado no dia 8 de dezembro de 2010, obtendo-se população final de 62.500 plantas ha $^{-1}$. No momento da semeadura, realizou-se adubação de base com $300 \mathrm{~kg} \mathrm{ha}^{-1}$ da fórmula 5-25-25 e, posteriormente, a adubação de cobertura com $90 \mathrm{~kg} \mathrm{ha}^{-1}$ de nitrogênio na forma de ureia, dividida em duas aplicações, aos 30 e 45 dias após a emergência (DAE) da cultura.

$\mathrm{O}$ delineamento experimental utilizado foi de blocos casualizados, com quatro repetições, sendo cada unidade experimental constituída por área de $16 \mathrm{~m}^{2}$. Os tratamentos foram arranjados em esquema de parcelas subsubdivididas, sendo nas parcelas principais alocados os espaçamentos entrelinhas da semeadora $(0,4$ e $0,8 \mathrm{~m})$; nas subparcelas os herbicidas (tembotriona - $100 \mathrm{~g}$ i.a. ha ${ }^{-1} \mathrm{e}$ mesotriona - 192 g i.a. ha ${ }^{-1}$, com adição de adjuvante Aureo ${ }^{\circledR}$ na dose de $1 \mathrm{~L} \mathrm{ha}^{-1}$ e de Nimbus ${ }^{\circledR}$ na proporção de $0,5 \% \mathrm{v} / \mathrm{v}$ ); e, nas sub-subparcelas as doses dos herbicidas $(100 \%, 80 \%, 60 \%, 0 \%$ a dose recomendada).

Os herbicidas foram aplicados em estádio $\mathrm{V}_{5}$ do milho, com pulverizador costal pressurizado a $\mathrm{CO}_{2}$ com pontas de pulverização do tipo leque 110.015 (Micron Air $\left.^{\circledR}\right)$ e volume de calda de $150 \mathrm{~L} \mathrm{ha}^{-1}$. No momento da aplicação a temperatura média e a umidade relativa do ar foram em média de $26,8^{\circ} \mathrm{C}$ e $84 \%$, respectivamente. As principais plantas daninhas presentes na área foram Raphanus raphanistrum L. (nabo) e Urochloa plantaginea (Link) Hitchc. (papuã), as quais se encontravam, no momento da aplicação, em estádio de início de florescimento e 2 a 3 afilhos, respectivamente e em população de 86 e 83 plantas $\mathrm{m}^{2}$, respectivamente, em média de quatro contagens por bloco. 
Tabela 1. Dados médios de temperatura $\left({ }^{\circ} \mathrm{C}\right)$ e acumulados de precipitação pluviométrica $(\mathrm{mm})$ do período de condução de condução do experimento.

\begin{tabular}{lccccccc}
\hline & \multicolumn{7}{c}{ Mês/ano $^{1}$} \\
\cline { 2 - 7 } Condição climática & $12 / 10$ & $1 / 11$ & $2 / 11$ & $3 / 11$ & $4 / 11$ & $5 / 11$ & $6 / 11$ \\
\hline Temperatura média $\left({ }^{\circ} \mathrm{C}\right)$ & 22,2 & 24,9 & 23,5 & 21,5 & 18,5 & 15,0 & 12,4 \\
Precipitação pluviométrica $(\mathrm{mm})$ & 75,3 & $65,7^{1}$ & 90,91 & 144,4 & 111,5 & 118,3 & 116,2 \\
\hline
\end{tabular}

${ }^{1}$ Meses com complementação de precipitação por irrigação.

Fonte: Boletim Agroclimatológico - Estação Agroclimatológica de Pelotas.

Avaliaram-se visualmente o controle de nabo e papuã e a fitotoxicidade a cultura aos 7 , 14,21 e 28 dias após o tratamento (DAT), atribuindo-se notas percentuais, onde a nota zero correspondeu à ausência de injúrias e a nota 100 significou morte das plantas (Frans, 1972). Ao final do ciclo da cultura, avaliou-se o número de plantas parcela ${ }^{-1}$ e espigas planta ${ }^{-1}$, massa de mil grãos e produtividade. $\mathrm{O}$ número de plantas e espigas por parcela foi realizado pela contagem direta, enquanto que a massa de mil grãos foi realizada pela pesagem de cinco subamostras de cem grãos de cada parcela, com os valores ajustados a $13 \%$ de umidade. A produtividade foi calculada pelo peso de grãos obtidos na área útil de $4,8 \mathrm{~m}^{2}$, com posterior padronização da umidade para $13 \%$.

Os dados foram analisados quanto à normalidade pelo teste de Shapiro-Wilk e à homocedasticidade pelo teste de Hartley e, posteriormente, submetidos à análise de variância $(p \leq 0,05)$. Em caso de significância, os efeitos de espaçamento e herbicida foram analisados pelo teste $\mathrm{t}(\mathrm{p} \leq 0,05)$, e os efeitos de dose por modelo de regressão não linear $(\mathrm{p} \leq 0,05)$, representado pela equação 1 para níveis de controle e pela equação 2 para produtividade.

$$
\mathrm{y}=\mathrm{a}\left(1-\mathrm{e}^{-\mathrm{bx}}\right) \text { Equação } 1
$$

Onde: $y$ - \% de controle; $a$ - valor máximo estimado para a variável resposta $(\leq 100,0) ; b$ - inclinação da curva; $x$ - doses dos herbicidas mesotriona e tembotriona (g i.a. ha $\left.{ }^{1}\right) ; e$ - constante;

$$
y=y_{o}+a\left(1-e^{-b x}\right) \text { Equação } 2
$$

Onde: $y$ - produtividade $\left(\mathrm{kg} \mathrm{ha}^{-1}\right) ; y_{o}$ mínimo produtividade $\left(\mathrm{kg} \mathrm{ha}^{-1}\right) ; a$ - valor mínimo estimado para a variável resposta; $b$ inclinação da curva; $x$ - dose dos herbicidas mesotriona e tembotriona (g i.a. ha $\left.{ }^{-1}\right) ; e$ constante.

\section{Resultados e Discussão}

Não se verificou interação entre os fatores estudados, assim como significância estatística do fator espaçamento para nenhuma das variáveis testadas (dados não apresentados). Observou-se interação entre os fatores herbicida e dose para a variável controle das plantas daninhas aos 7, 14, 21 e 28 DAT (Figuras 1 e 2; Tabela 2) e efeito principal do fator dose, para a variável produtividade (Figura 3). Para as variáveis fitotoxicidade, número de espigas parcela $^{-1}$, espigas planta ${ }^{-1}$ e massa de mil grãos, não foi observada significância estatística para nenhum fator testado.

As aplicações de mesotriona ou tembotriona não ocasionaram fitotoxicidade à cultura (dados não apresentados), confirmando a seletividade destes herbicidas ao milho (Zagonel \& Fernandes, 2007). Isto decorre das plantas de milho terem a capacidade de metabolizá-los rapidamente, produzindo metabólitos sem atividade tóxica (Karam et al., 2010).

O controle de nabo e papuã não apresentou diferença significativa entre os herbicidas mesotriona e tembotriona aos 7 
DAT, independentemente das doses testadas (Tabela 2). Observaram-se diferenças entre os herbicidas no controle das duas espécies a partir dos 14 DAT, sendo que o herbicida tembotriona foi mais eficiente para o controle de papuã, enquanto mesotriona para o controle de nabo.

Em trabalho realizado com Bidens pilosa L., Digitaria horizontalis Willd. e $U$. plantaginea (Link) Hitchc., utilizando mesotriona e tembotriona, o controle dessas espécies foi acima de $80 \%$ pela aplicação de ambos herbicidas, sendo somente observada diferença de controle para B. pilosa, onde o mesotriona foi mais eficiente (Zagonel \& Fernandes, 2007). Por outro lado, a aplicação de mesotriona em pós-emergência de milho evidenciou que o herbicida é eficiente no controle de Ipomoea sp. e Amaranthus spp., porém apresentou menor eficiência sobre espécies poaceas (Johnson et al., 1999). Desse modo, pode se inferir que o produtor deve escolher o herbicida mais adequado de acordo com as espécies daninhas presentes na área, utilizando tembotriona quando há predominância de poaceas, e mesotriona para dicotiledôneas.

Observou-se que o controle de nabo foi próximo a $95 \%$ por meio da aplicação de mesotriona, sendo considerado aceitável (Tabela 2). Já para tembotriona, a maior eficiência de controle foi para papuã, estando os níveis próximos a $78 \%$. O baixo nível de controle de papuã pode ser atribuído à alta infestação desta planta daninha na área e ao estádio avançado das mesmas (2-3 afilhos), promovendo efeito guarda-chuva no momento da aplicação. Em estudo que avaliou a associação de tembotriona com atrazina, prática usual entre os produtores para 0 aumento do espectro e controle residual de plantas daninhas, não se verificou ineficiência de controle de papuã (Zagonel \& Fernandes, 2007). Desse modo, é importante ressaltar que o estádio fenológico da planta daninha e a época de aplicação devem ser analisados cuidadosamente antes da aplicação do herbicida, sob pena da redução do controle de plantas daninhas.

Tabela 2. Controle (\%) de nabo (Raphanus raphanistrum L.) e papuã (Urochloa plantaginea (Link) Hitchc.) em função da aplicação dos herbicidas tembotriona e mesotriona em dose plena (100\%) e doses reduzidas ( $80 \%$ e $60 \%)$, aos 7, 14, 21 e 28 dias após o tratamento (DAT)

\begin{tabular}{|c|c|c|c|c|c|}
\hline \multirow{2}{*}{ Planta daninha/Época de avaliação } & \multirow{2}{*}{ Herbicida } & \multicolumn{4}{|c|}{ Dose (\%) } \\
\hline & & 0 & 60 & 80 & $100^{1}$ \\
\hline \multirow{2}{*}{ Nabo/7 DAT } & tembotriona & $0^{\mathrm{ns}}$ & $54^{\mathrm{ns}}$ & $59^{\mathrm{ns}}$ & $60^{\mathrm{ns}}$ \\
\hline & mesotriona & 0 & 58 & 61 & 64 \\
\hline \multirow{2}{*}{ Papuã/7 DAT } & tembotriona & $0^{-n s^{-1}}$ & $57^{-\mathrm{ns}^{-}}$ & $63^{-n s-7}$ & $64^{-n^{-1}}$ \\
\hline & mesotriona & 0 & 60 & 64 & 68 \\
\hline \multirow{2}{*}{ Nabo/14 DAT } & tembotriona & $0^{\mathrm{ns}}$ & 44 & 53 & 59 \\
\hline & mesotriona & 0 & 68 & 74 & 78 \\
\hline \multirow{2}{*}{ Papuã/14 DAT } & tembotriona & $00^{\text {nis- }}$ & 64 & 68 & 72 \\
\hline & mesotriona & 0 & 49 & 51 & 65 \\
\hline \multirow{2}{*}{$\mathrm{Nabo} / 21 \mathrm{DAT}$} & tembotriona & $0^{\mathrm{ns}}$ & 50 & 65 & 74 \\
\hline & mesotriona & 0 & 85 & 91 & 94 \\
\hline \multirow{2}{*}{ Papuã/21 DAT } & tembotriona & 0 & 68 & 77 & 86 \\
\hline & mesotriona & 0 & 38 & 43 & 56 \\
\hline \multirow{2}{*}{ Nabo/28 DAT } & tembotriona & $0^{\mathrm{ns}}$ & 53 & 57 & 63 \\
\hline & mesotriona & 0 & 84 & 91 & 95 \\
\hline \multirow{2}{*}{ Papuã/28 DAT } & tembotriona & $0^{n-1 s^{-}}$ & 70 & 78 & 78 \\
\hline & mesotriona & 0 & 37 & 48 & 55 \\
\hline
\end{tabular}

${ }^{1}$ Dose do produto comercial Callisto ${ }^{\circledast}\left(192 \mathrm{~g}\right.$ i.a. ha $\left.{ }^{-1}\right)$ e $\operatorname{Soberan}^{\circledR}\left(100 \mathrm{~g}\right.$ i.a. ha $\left.{ }^{-1}\right){ }^{*} \mathrm{e}^{\text {ns }}$, significativo e não significativo, respectivamente, pelo teste $\mathrm{t}(\mathrm{p} \leq 0,05)$ comparando os herbicidas dentro de cada dose. 
Em relação às doses dos herbicidas, os ajustes dos modelos aos dados foram considerados satisfatórios para ambas as espécies de plantas daninhas, sendo que o coeficiente de determinação $\left(\mathrm{R}^{2}\right)$ variou de 0,86 a 0,99 (Figuras 1 e 2). Em todas as épocas de avaliação, o controle de nabo pela aplicação dos herbicidas em dose $100 \%$, ou mesmo com redução de $20 \%$ da mesma não apresentou diferença significativa (Figura 1).
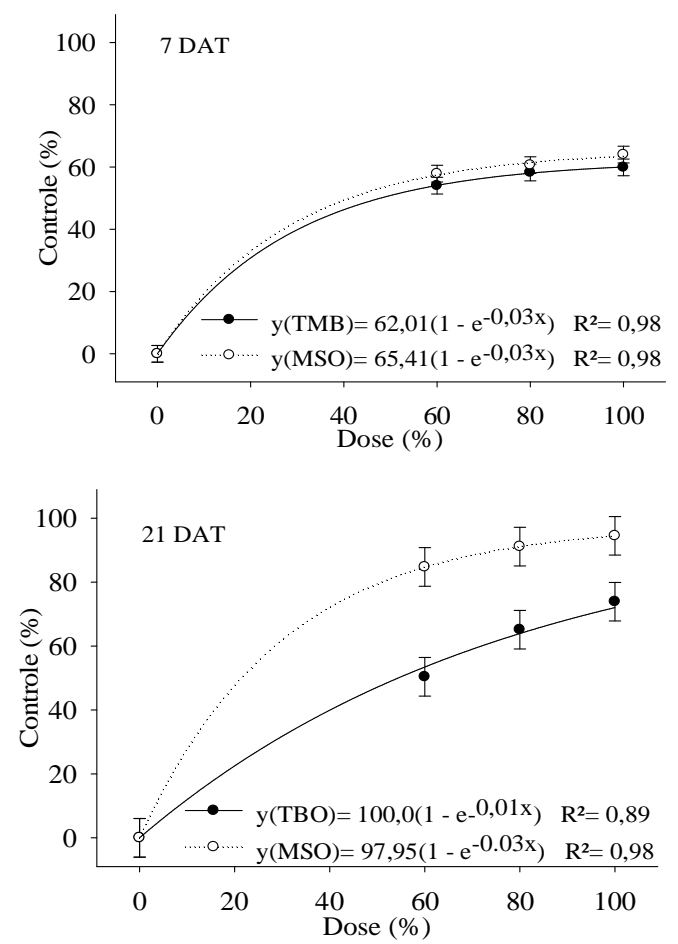

Resultado similar foi observado para o controle de papuã aos 28 DAT, onde a redução em $20 \%$ da dose não alterou o controle de ambos os herbicidas em nenhuma das avaliações (Figura 2). A aplicação de doses menores que as recomendadas do herbicida mesotriona foram eficientes no manejo de algumas espécies de plantas daninhas (Nurse et al., 2010).
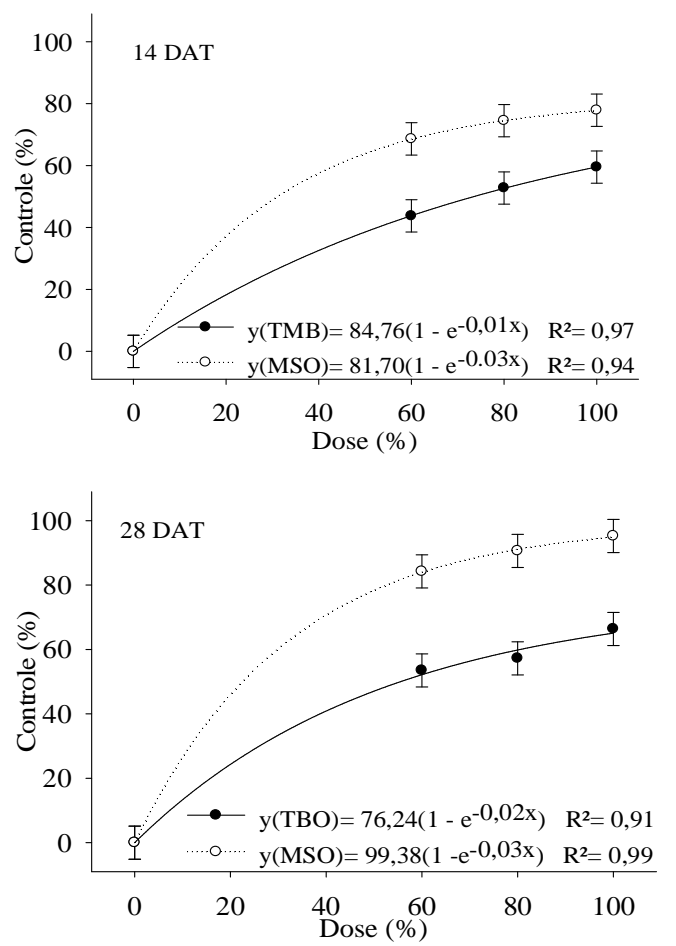

Figura 1. Controle de nabo (Raphanus raphanistrum L.) aos 7, 14, 21 e 28 dias após o tratamento (DAT) em função de doses dos herbicidas tembotriona (TMB) e mesotriona (MSO). Barras verticais representam os intervalos de confiança das médias $(\mathrm{p} \leq 0,05)$. 

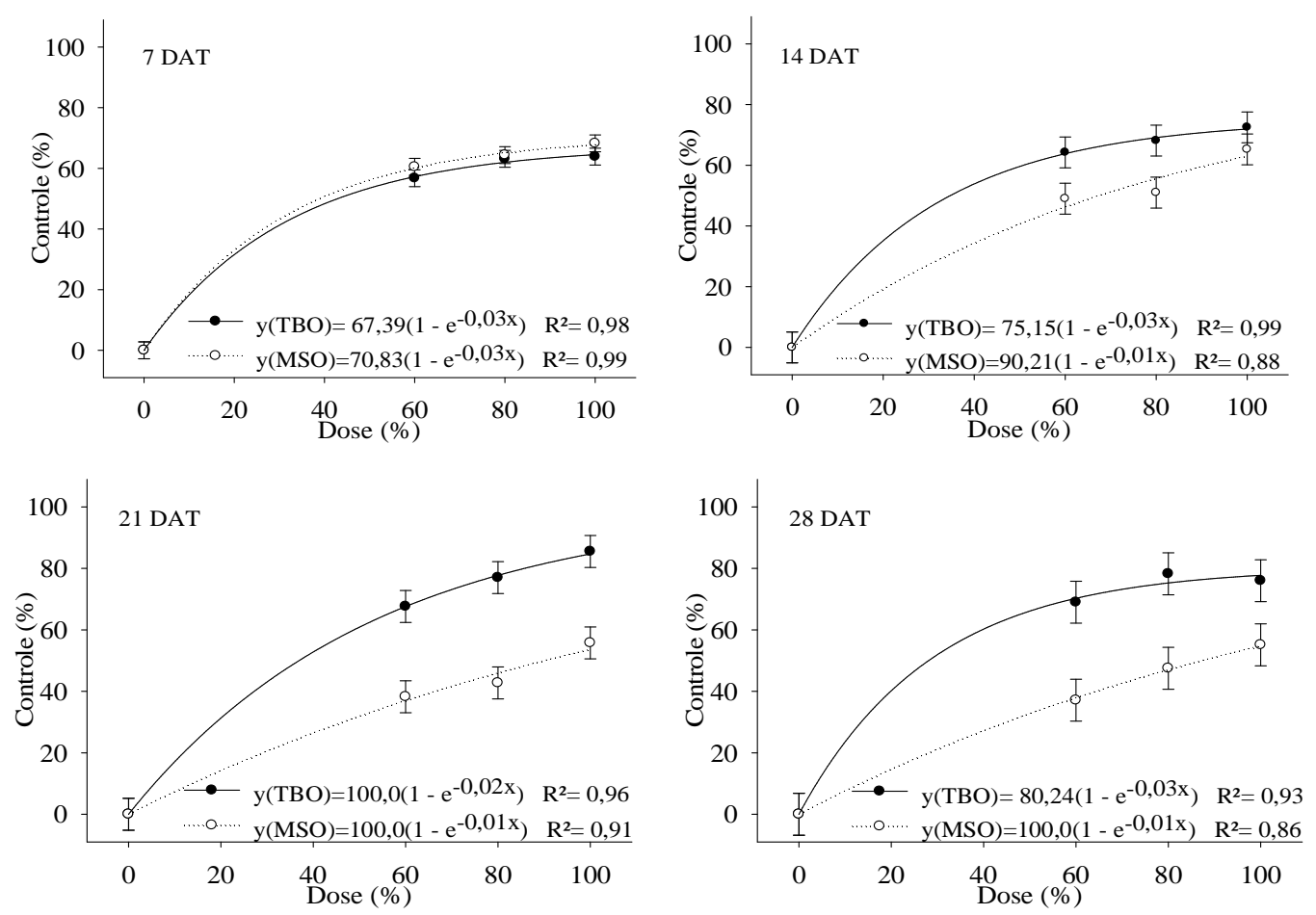

Figura 2. Controle de papuã (Urochloa plantaginea (Link) Hitchc.) aos 7, 14, 21 e 28 dias após o tratamento (DAT) em função de doses dos herbicidas tembotriona (TMB) e mesotriona (MSO). Barras verticais representam os intervalos de confiança das médias $(\mathrm{p} \leq 0,05)$.

A redução da dose do herbicida está condicionada à época de aplicação e ao espaçamento entre linhas. Nesse sentido, com espaçamentos reduzidos é importante que as aplicações sejam realizadas precocemente, a fim de garantir que quantidade suficiente de produto atinja as plantas daninhas (Pires et al., 2001). Contudo, na presente pesquisa não foram observadas diferenças entre os espaçamentos para a eficiência dos herbicidas e doses desses nas plantas daninhas analisadas.

Em estudo que testou a aplicação de diferentes herbicidas em milho cultivado com diferentes espaçamentos, foi verificado que somente para as aplicações em pós-emergência precoce houve diferença para o controle de $U$. plantaginea (Link) Hitchc., Euphorbia heterophylla L. e Avena strigosa Schreb., em que o desenvolvimento dessas plantas foi superior no maior espaçamento (Trezzi et al., 2008). Desse modo, é importante ressaltar que a redução da dose de herbicidas não pode ser feita sem antes avaliar alguns fatores, tais como: produto utilizado, método de aplicação, espécie daninha e estádio de desenvolvimento (Fleck, 1994). Além disso, a eficiência de controle não deve ser o único fator a ser considerado para a decisão de reduzir a dose do herbicida, devendo-se atentar a possibilidade de reinfestação de plantas daninhas nas safras seguintes e a produtividade de grãos.

Para a variável produtividade de grãos, o modelo exponencial utilizado propiciou bom ajuste aos dados, representado pelo $\mathrm{R}^{2}$ de 0,99 (Figura 3). A aplicação de herbicida proporcionou maior produtividade comparada à testemunha sem controle, sendo a produtividade desta aproximadamente $40 \%$ inferior a observada na média das doses herbicidas. Assim, fica evidente que a ausência de método de controle permite o desenvolvimento das plantas daninhas que exercem competição pelos recursos do meio, interferindo no desenvolvimento da cultura. Já, 
as doses de $80 \%$ e $60 \%$, comparativamente a máxima dose testada, apresentaram redução na produtividade de $2,5 \%$ e $8,7 \%$, respectivamente, entretanto sem diferença significativa (Figura 3). De modo semelhante ao verificado neste trabalho, Nurse et al. (2010) também constataram que a aplicação de doses menores que as recomendadas do herbicida mesotriona, até determinado ponto, não apresentaram diferenças entre as produtividades obtidas.

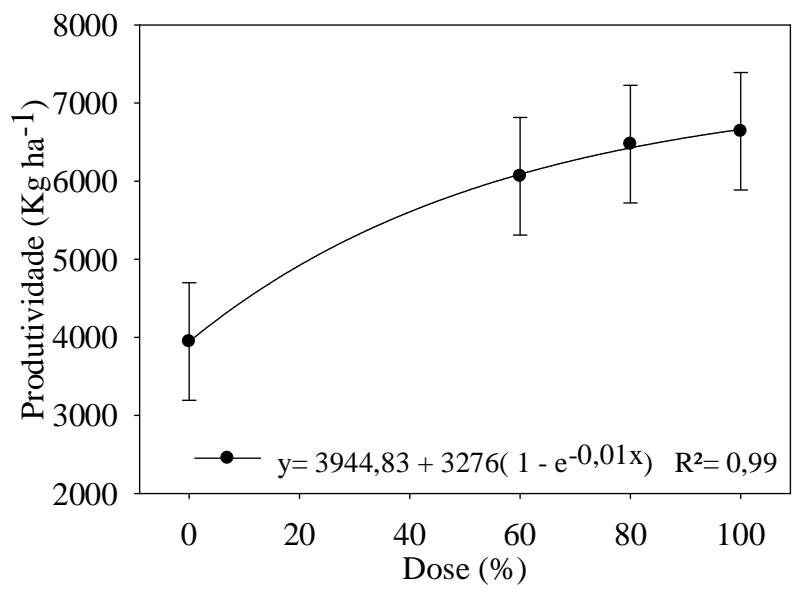

Figura 3. Produtividade média $\left(\mathrm{kg} \mathrm{ha}^{-1}\right)$ em função de doses dos herbicidas tembotriona e mesotriona. Barras verticais representam os intervalos de confiança das médias $(p \leq 0,05)$.

Independente de não ocorrer interação dos fatores testados e do uso da dose recomendada, esperava-se maior controle e produtividade no espaçamento de $0,40 \mathrm{~m}$ em relação ao de $0,80 \mathrm{~m}$. Alguns trabalhos evidenciam que espaçamentos reduzidos, até determinado limite, mantendo-se as mesmas populações de plantas por unidade de área, proporcionam maiores produtividades (Argenta et al., 2001; Shresta et al., 2001; Johnson \& Hoverstad, 2002; Strieder, 2006). Um problema do uso de espaçamentos reduzidos é que, algumas vezes, a infestação de plantas daninhas na linha de semeadura é maior do que nas entrelinhas (Bianchi, 1998; Vidal \& Trezzi, 2004), o que pode ocasionar maior infestação por área.

A falta de resposta da produtividade à redução de espaçamento das entrelinhas pode estar associada à população de plantas da cultura. Para população de 65.000 plantas ha ${ }^{-1}$ não houve efeito do espaçamento sobre a produtividade de grãos de milho (Argenta et al., 2001), sendo essa população semelhante à utilizada nesse estudo. Esta resposta pode ocorrer pela maior competição por luz entre plantas de milho de linhas diferentes (Tollenaar et al., 1992), alterando o tipo de competição. Entretanto, a redução de espaçamento pode promover o sombreamento precoce do solo, prejudicando o desenvolvimento de plantas daninhas nas entrelinhas, sendo assim o efeito benéfico.

Menores espaçamentos entrelinhas permitem melhor distribuição espacial das plantas de milho, aumentando a competitividade da cultura e a eficiência na intercepção da luz (Flénet et al., 1996; Argenta et al., 2001; Balbinot Junior \& Fleck, 2005), podendo favorecer a produtividade de grãos. Contudo, a maior eficiência de interceptação da radiação fotossinteticamente ativa em espaçamento reduzido não resulta em maior eficiência de sua utilização (Kunz et al., 2007), o que pode não interferir na produtividade. 


\section{Conclusões}

A redução do espaçamento não interferiu no controle das plantas daninhas nabo (Raphanus raphanistrum L.) e papuã (Urochloa plantaginea (Link) Hitchc.) e na produtividade do milho híbrido 2B65HX. O herbicida mesotriona foi mais eficiente no controle de nabo e o tembotriona de papuã, possibilitando utilizar $80 \%$ da dose recomendada de ambos sem afetar o controle de plantas daninhas e a produtividade da cultura.

\section{Referências}

ARGENTA, G. et al. Resposta de híbridos simples de milho à redução do espaçamento entre linhas. Pesquisa Agropecuária Brasileira, v.36, n.1, p.71-78, 2001.

BALBINOT JUNIOR, A.A.; FLECK, N.G. Manejo de plantas daninhas na cultura de milho em função do arranjo espacial de plantas e características dos genótipos. Ciência Rural, v.35, n.1, p.245-252, 2005.

BIANCHI, M. Manejo integrado de plantas daninhas. In: CAMPOS, B. H. C. A cultura do milho no plantio direto. Cruz Alta: Fundacep Fecotrigo, 1998. p.128-143.

\section{BOLETIM AGROCLIMATOLÓGICO.}

Estação Agroclimatológica de Pelotas. Disponível em: <http://www.cpact.embrapa.br/ agromet/estacao/boletim.html>. Acesso em: 23 jan. 2014.

DEFELICE, M.S. et al. Weed control in soybeans (Glycine max) with reduced rates of postemergence herbicides. Weed Science, v.37, n. 3, p.365-374, 1989.

DEMÉTRIO, C.S. et al. Desempenho de híbridos de milho submetidos a diferentes espaçamentos e densidades populacionais. Pesquisa Agropecuária Brasileira, v.43, n.12, p.1691-1697, 2008.
EMBRAPA. Empresa Brasileira de Pesquisa Agropecuária. Centro Nacional de Pesquisa de Solos. Sistema Brasileiro de Classificação de Solos. Brasília: 2006. 306p.

FAO. Food and Agriculture Organization of the United Nations. Production of cereals and share in world. Disponível em: http://faostat.fao.org/site/567/DesktopDefault.a spx. Acesso em: 10 abr. 2013.

FLECK, N.G et al. Dose reduzida de clethodim no controle de papuã na cultura da soja, em função da época de aplicação. Planta Daninha, v.15, n.1, p.18-24, 1997.

FLECK, N.G. Doses reduzidas de herbicidas de pós-emergência para controle de papuã em soja. Planta Daninha, v.12, n.1, p.21-28, 1994.

FLÉNET, F. et al. Row spacing effects on light extinction coefficients of corn, sorghum, soybean, and sunflower. Agronomy Journal, v.88, n.2, p.185-190, 1996.

FRANS, R.E. Measuring plant responses. In: Wilkinson, R.E. (Ed.). Research methods in weed science. Atlanta: Southern Weed Science Society, 1972. p.27-41.

JOHNSON, G.A.; HOVERSTAD, T.R. Effect of row spacing and herbicide application timing on weed control and grain yield in corn (Zea mays). Weed Technology, v.16, n.3, p.548-553, 2002.

JOHNSON, W.G. et al. Mesotrione programs. North Central Weed Science Society Research Report, v.56, n.1, p.225-226, 1999.

KARAM, D. et al. Sistemas de Produção: Cultivo de milho. Sete Lagoas: Embrapa Milho e Sorgo, $6^{\circ}$ ed., 2010. Disponível em: http://ainfo.cnptia.embrapa.br/digital/bitstream/ item/ 27041/1/Plantas-daninhas.pdf. Acesso em: 12 jun. 2012

KUNZ, J.H et al. Uso da radiação solar pelo milho sob diferentes preparos do solo, espaçamento e disponibilidade hídrica. 
Pesquisa Agropecuária Brasileira, v.42, n.11, p.1511-1520, 2007.

NICE, G.R.W. et al. Sicklepod (Senna obtusifolia) response to shading, soybean (Glycine max) row spacing, and population in three management systems. Weed Technology, v.15, n.1, p.155-162, 2001.

NORRIS, R.F. et al. Spatial arrangement, density, and competition between barnyardgrass and tomato: I. Crop growth and yield. Weed Science, v.49, n.1, p.61-68, 2001.

NUNES, A.L. et al. Potencial de supressão de plantas daninhas na cultura do milho (Zea mays) com uso de diferentes híbridos, espaçamentos entre linhas e níveis de herbicidas em pós-emergência. In: XXIV Congresso Brasileiro da Ciência das Plantas Daninhas, 2004, São Pedro. Anais... Londrina: SBCPD, 2004. p.233.

NURSE, R.E. et al. Weed control and yield response to mesotrione in maize (Zea mays). Crop Protection, v.29, n.7, p.652-657, 2010.

OTTMAN, M.J.; WELCH, L.F. Planting patterns and radiation interception, plant nutrient concentration, and yield in corn. Agronomy Journal, v.81, n.2, p.167-174, 1989.

PIRES, J.L.F. et al. Redução na dose do herbicida aplicado em pós-emergência associada a espaçamento reduzido da cultura de soja para controle de Brachiaria plantaginea. Planta Daninha, v.19, n.3, p.337-343, 2001.

SHRESTA, A. et al. An integrated weed management strategy for glufosinate-resistant corn (Zea mays). Weed Technology, v.15, n.4, p.517-522, 2001.

STRIEDER, M.L. Resposta do milho à redução do espaçamento entre linhas em diferentes sistemas de manejo. Porto Alegre: Universidade Federal do Rio Grande do Sul, 2006. 94 p. Dissertação Mestrado.
TEASDALE, J.R. Influence of narrow row/high population corn on weed control and light transmittance. Weed Technology, v.9, n.1, p.113-118, 1995.

THARP, B.E.; KELLS, J.J. Effect of glufosinate-resistant corn (Zea mays) population and row spacing on light interception, corn yield, and common lambsquarters (Chenopodium album) growth. Weed Technology, v.15, n.3, p.413-418, 2001.

TOLLENAAR, M. et al. Ear and kernel formation in maize hybrids representing three decades of grain yield improvement in Ontario. Crop Science, v.32, n.2, p.432-438, 1992.

TREZZI, M.M. et al. Manejo químico de plantas daninhas na cultura do milho em função de características morfofisiológicas e redução de espaçamento da cultura. Planta Daninha, v.26, n.4, p.845-853, 2008.

VARGAS, L. et al. Manejo das plantas daninhas do milho. Passo Fundo-RS: Embrapa Trigo, Documentos Online, 61, 2006. Disponível em: http://www.cnpt.embrapa.br/ biblio/do/ $p$ do61.pdf. Acesso em: 10 jun. 2012.

VIDAL, R.A. Ação dos herbicidas: Absorção, translocação e metabolização. Porto Alegre, v.1, 2002. 89p.

VIDAL, R.A.; TREZZI, M.M. Potencial de utilização de cobertura vegetal de sorgo e milheto na supressão de plantas daninhas na condição de campo I- Plantas em desenvolvimento vegetativo. Planta Daninha, v.22, n.2, p.217-223, 2004.

ZAGONEL, J.; FERNANDES, E.C. Controle de plantas daninhas e seletividade do herbicida tembotrione na cultura do milho. Revista Brasileira de Herbicidas, v.6, n.2, p.42-49, 2007. 